\title{
ASPECTOS ÉTICOS NA AÇÃO GERENCIAL DO ENFERMEIRO
}

\author{
Maria Auxiliadora Trevizan ${ }^{1}$ \\ Isabel Amélia Costa Mendes ${ }^{1}$ \\ Maria Regina Lourenço ${ }^{2}$ \\ Gilberto Tadeu Shinyashiki ${ }^{3}$
}

Trevizan MA, Mendes IAC, Lourenço MR, Shinyashiki GT. Aspectos éticos na ação gerencial do enfermeiro. Rev Latino-am Enfermagem 2002 janeiro-fevereiro; 10(1):85-9.

Com o propósito de abordar aspectos éticos na ação gerencial do enfermeiro, os autores evocam Etzioni ${ }^{(1)}$ e adotam uma classificação de hospital como uma referência de organização, onde o consentimento é baseado na internalização de regras aceitas como legítimas. No caso do paciente, a necessidade de adaptação ao comportamento médico e regras hospitalares, através da internalização, é vista como devida ao poder do médico, do enfermeiro e do hospital. Na nossa visão, esta internalização ocorre de uma maneira ingênua, sem consentimento, desde que a maioria dos pacientes brasileiros não sabe que pode, ou não, consentir porque está acostumada a obedecer. Os autores enfocam a função gerencial do enfermeiro, indicando que esta deve ser baseada em valores da profissão, em seu código de ética e nos direitos do paciente hospitalizado, integrando cuidado humano qualificado, guiado pelo respeito, por livre consentimento e pela promoção do paciente como um protagonista e sujeito do cuidado.

DESCRITORES: ética, enfermagem, administração, gerenciamento, direitos do paciente

\section{ETHICAL ASPECTS CONCERNING NURSES' MANAGERIAL ACTIVITY}

Aiming at addressing the ethical aspects concerning nurses' managerial activities, the authors of this work referred to Etzioni ${ }^{(1)}$ and adopted a hospital classification as a reference of organization in which consent is based on the internalization of rules accepted as legitimate. Regarding patients, their need to adapt to medical behavior and hospital rules through internalization is considered to be a result of physicians', nurses' and the hospital's power. However, the authors view that such internalization is naive, without consent, especially by taking into account that most Brazilian patients do not know that they should or should not consent and are used to obeying. Thus, the work focused on nurses' managerial actions, indicating that they must be based on professional values, the Nursing ethical code as well as on the rights of hospitalized patients, thus integrating qualified care guided by respect, free consent and promotion of patients as the protagonists and subjects of care.

KEY WORDS: ethic, nursing, administration, management

\section{ASPECTOS ÉTICOS EN LA ACCIÓN GERENCIAL DEL ENFERMERO}

Con el propósito de tratar aspectos éticos en la acción gerencial del enfermero, las autoras evocan Etzioni y adoptan una clasificación del hospital como una referencia de organización en la cual, el consentimiento se basa en la internalización de reglas aceptas como legítimas. En el caso del paciente, la necesidad de adaptación al comportamiento médico y a las reglas hospitalarias, a través de la internalización, es vista como derivada del poder del médico, del enfermero y del hospital. En nuestra visión, ésta internalización ocurre de forma ingenua, sin consentimiento, desde que la mayoría de los pacientes brasileños no sabe que puede, o no, consentir por que están acostumbrados a obedecer. Las autoras enfocan la función gerencial del enfermero, indicando que ésta debe estar basada en los valores de la profesión, su código de ética y los derechos de los pacientes hospitalizados, integrando un cuidado calificado, orientado por el respeto, el libre consentimiento y por la promoción del paciente como protagonista y sujeto del cuidado.

DESCRIPTORES: ética, enfermería, administración, gerenciamiento

\footnotetext{
${ }_{1}^{1}$ Pesquisador 1-A CNPq e Professor Titular, e-mail: iamendes@eerp.usp.br. Escola de Enfermagem de Ribeirão Preto da Universidade de São Paulo, Centro Colaborador da OMS para o desenvolvimento da pesquisa em enfermagem; ${ }^{2}$ Gerente do Serviço de Enfermagem da Santa Casa de São José do Rio Preto e doutoranda da área de Enfermagem Fundamental da Escola de Enfermagem de Ribeirão Preto da Universidade de São Paulo; ${ }^{3}$ Professor Doutor da Faculdade de Administração, Economia e Contabilidade da Universidade de São Paulo, Campus Ribeirão Preto, Psicólogo e Diretor do Departamento de Recursos Humanos da Reitoria da Universidade de São Paulo
} 


\section{INTRODUÇÃO}

Ao analisar comparativamente as organizações complexas, Etzioni ${ }^{(1)}$ fundamentou-se no consentimento, considerando ser este um elemento central da estrutura organizacional, dada a sua universalidade como ingrediente básico nas relações de poder. Em outros termos, consentimento é utilizado para desenvolver uma base analítica que permuta classificar as organizações, segundo: a) identificação de três tipos de poder coercivo, remunerativo e normativo; b) especificação de três tipos de participação - alienativa, calculista e moral; e, finalmente, c) associando os tipos de poder com os tipos de participação associações essas que constituem as relações de consentimento e, como mencionamos, serviram ao autor para fundamentar a classificação de organizações.

Nas organizações denominadas normativas "o poder normativo é a principal fonte de controle sobre a maioria dos participantes dos níveis inferiores, cuja orientação para com a organização é caracterizada pelo alto engajamento"(1). 0 consentimento nessas organizações apoia-se, sobretudo, na internalização das diretrizes aceitas como legítimas. Aqui, a liderança, a manipulação de símbolos de prestígio e símbolos sociais e a ressocialização constituem os procedimentos mais importantes de controle.

O hospital, caracterizado como a organização mais complexa do sistema de cuidado à saúde, classifica-se como organização normativa, embora, "haja pouca informação concernente às formas segundo as quais os pacientes são controlados"; contudo, 0 autor admite que "a necessidade do paciente de aceitar as regras do jogo é altamente internalizada"(1).

Em termos dos mecanismos psicológicos para o ajustamento à influência, no processo de internalização o receptor acolhe a idéia ou proposta como sua, e então internaliza-a de maneira que a mesma passa a ser um de seus bens ${ }^{(2)}$. Seguindo a mesma lógica, entendemos, como o autor, que a internalização é o modo de comprometimento mais almejado pelas organizações. No caso do paciente, de modo geral, podemos inferir que sua necessidade de adaptar-se reagindo através do mecanismo da internalização decorra das fontes de poder oriundas do médico, do enfermeiro* e da organização que 0 admite. Em outros termos, a definição do diagnóstico e tratamento do paciente emana do conhecimento médico, a administração do hospital fornece os recursos necessários aos procedimentos médicos e o enfermeiro, por sua vez, executa tais ordens ou as transmite a outros departamentos do hospital, cumprindo sua ação coordenadora e gerencial. Ainda, ao paciente, o enfermeiro transmite instruções do hospital, assim como instruções relativas às prescrições médicas assegurando, então, o cumprimento destas ordens e controlando sua obediência a elas e ao regulamento hospitalar. Em suma, a administração do hospital assegura a disponibilidade de todos os serviços necessários em potencial, o médico seleciona os serviços a serem prestados e o enfermeiro executa e controla a prestação de serviços. Cada um desses três papéis é vital para o funcionamento dos hospitais na forma em que eles estão estruturados atualmente ${ }^{(3)}$. Nesse contexto, as enfermeiras desempenham um papel central na estrutura - mas não aquele que a enfermagem profissional dita. Analise sobre a ética convencional do gerenciamento do enfermeiro apontou a preocupação, por parte da enfermagem brasileira, com o estabelecimento de uma nova ética para pautar a conduta gerencial desse profissional tornando-a mais sintonizada aos valores profissionais e às prioridades do paciente ${ }^{(4)}$.

Ademais, em nosso meio as orientações emanadas do médico, do enfermeiro e da alta administração hospitalar constituemse em ordens que os pacientes sentem que precisam cumprir para seu próprio bem, agindo passiva e pacientemente em relação às mesmas, o que nos permite inferir também o desconhecimento dos pacientes - de modo geral - em relação a seus direitos. Assim, poderíamos dizer que eles adotam a internalização norteados pelo precário conhecimento sobre seus direitos, pela crença no poder quase infalível do médico e pela confiança nas orientações provenientes do enfermeiro em relação ao cuidado prestado e ao atendimento das necessidades disciplinares da instituição hospitalar. Em síntese, acreditamos que a internalização dessas ordens por parte dos pacientes se dê de forma ingênua e sem atentar para a questão do consentimento, uma vez que eles nem sabem que podem consentir, pois estão acostumados a obedecer. Entretanto, o Código de Ética dos Profissionais de Enfermagem, em seu Capítulo V, Artigo 44 , proíbe aos profissionais de enfermagem "participar de tratamento sem o consentimento do cliente ou representante legal, exceto em iminente risco de vida"(5).

Assim, considerando a relevância do problema, o propósito deste artigo é abordar aspectos éticos na ação gerencial do enfermeiro.

\footnotetext{
* sobre poder do enfermeiro, Trevizan (1988) aponta que a indicação desses profissionais para ocuparem cargos administrativos é feita por autoridade superior e assim investem-se de autoridade decorrente do regulamento da instituição, através de delegação. Investidos de autoridade, e assumindo a responsabilidade inerente, passam a se comprometer com os objetivos da organização; isto é, não agem apenas em conformidade com as normas padronizadas, mas são responsáveis também por manter essa normatização
} 
AÇÃO GERENCIAL DO ENFERMEIRO: IMPORTÂNCIA DOS VALORES DA PROFISSÃO, DO CÓDIGO DE ÉTICA E DOS DIREITOS DO PACIENTE

O exercício da função gerencial pelo enfermeiro no Brasil é uma questão ainda mesclada por desentendimentos e incompreensões. $O$ fato de ele incorporar funções gerenciais no seu trabalho, em grau considerado acentuado por alguns autores, tem sido a causa de muita polêmica na profissão. Esta polêmica avulta na medida em que se torna evidente a dicotomia entre o que se espera do enfermeiro na visão dos teóricos de enfermagem e o que se verifica ser a sua ação cotidiana nas instituições de saúde.

Ao inserirem-se no âmago de uma organização, os enfermeiros deparam-se com um trabalho que os leva a uma conduta organizada segundo rotinas preestabelecidas; deles é esperado que cumpram normas e regulamentos burocráticos, observem a hierarquia de autoridade e não se desviem para o novo e inesperado, ou para fatos não contemplados no esquema.

No nosso entender, a prática profissional do enfermeiro deve prender-se à assunção da função gerencial centrada na assistência ao paciente, a qual será norteada pela compreensão e pelo conhecimento do paciente como pessoa, e de suas necessidades específicas. Este conhecimento orientará as ações do enfermeiro no sentido de implementar a assistência de enfermagem que os pacientes necessitam. Assim compreendido, este exercício gerencial reside na gerencia da assistência de enfermagem, além de envolver a implementação das ordens médicas e as expectativas da organização hospitalar, uma vez que todo serviço administrativo é fundamentalmente interdependente, 0 que significa complementaridade e interrelação, e não apenas o manuseio de tráfegos de influências e de adaptações de dependência ${ }^{(6)}$.

Nesta ótica, estão implícitas algumas atitudes por parte do enfermeiro. Ele deve, em princípio, deixar de ser simples executor de tarefas ditadas por outros, ou por normas, assumir a autodeterminação de suas funções e ajustar princípios e medidas administrativas à solução de problemas específicos de sua área. Para tanto, ele utilizará sua criatividade ao planejar as ações de enfermagem, ao tomar decisões e ao adequar os recursos humanos e materiais à implementação da assistência planejada e desejada.

Nesse prisma, a ação ou a prática do enfermeiro é criadora e, portanto, determinante, já que é justamente esta prática que permite a ele enfrentar novas necessidades, novas situações ${ }^{(7)}$.

Entendemos que, deste modo, o enfermeiro estará cumprindo o que determina a Lei $n^{0} 7.498$, de 25 de junho de 1986, que dispõe sobre a regulamentação do exercício da Enfermagem no Brasil; em seu artigo 11 determina que "o enfermeiro exerce todas as atividades de enfermagem, cabendo-Ihe privativamente: a) direção do órgão de enfermagem integrante da estrutura básica da instituição de saúde, pública e privada, e chefia de serviço e de unidade de enfermagem; b) organização e direção dos serviços de enfermagem e de suas atividades técnicas e auxiliares nas empresas prestadoras desses serviços; c) planejamento, organização, coordenação, execução e avaliação dos serviços de assistência de enfermagem; ... j) prescrição da assistência de enfermagem,....(8).

É imprescindível, contudo, que não se perca de vista que a ação gerencial do enfermeiro deverá ser fundamentada nos valores da profissão, no seu Código de Ética e nos direitos do paciente hospitalizado.

Nos valores da profissão estão embutidos o conhecimento atualizado e a autonomia do profissional para que, com competência, atinja através da ação gerencial uma assistência qualificada ao ser humano; em termos filosóficos práticos, este profissional deve procurar alcançar, por meio da ação, o bem do homem e nesse sentido integrar questões éticas no seu agir.

Segundo a visão de autores consagrados, "a ética profissional é uma parte da ciência moral. Mais do que limitar-se a um feixe de normas, ela procura a humanização do trabalho organizado, isto é, procura colocá-lo a serviço do homem, da sua promoção, da sua finalidade social. É tarefa ainda da ética profissional detectar os fatores que, numa determinada sociedade, esvaziam a atividade profissional tornando-a alienada. Mais do que formular determinadas normas e cristalizá-las num código, é tarefa da ética profissional realizar uma reflexão crítica, questionadora, que tenha, por finalidade, salvar o humano, a hipoteca social de toda atividade profissional" $^{\prime(9)}$.

O Código de Ética dos Profissionais de Enfermagem do Brasil, reestruturado e aprovado pelo Conselho Federal de Enfermagem, constitui numa declaração pública que visa 0 aprimoramento do comportamento ético do profissional, expressando questões morais, valores e metas da Enfermagem. Este código "leva em consideração, prioritariamente, a necessidade e 0 direito de assistência de enfermagem à população, os interesses do profissional e de sua organização. Está centrado na clientela e pressupõe que os agentes de trabalho da enfermagem estejam aliados aos usuários na luta por uma assistência de qualidade sem riscos e acessível a toda a população"(5).

Segundo nossa interpretação, o princípio de respeito pelo ser humano é considerado como o valor básico inserido naquele Código. Outros como autonomia, beneficência, veracidade, confidencialidade, fidelidade, privacidade, justiça, competência e responsabilidade oferecem apoio àquele valor básico.

A reflexão sobre tais princípios nos remete à tese defendida em nosso meio que propõe a alteridade como critério fundamental e 
englobante da Bioética, considerando que a beneficência, a autonomia e a justiça não são suficientes para responder aos prementes e contínuos problemas que a própria evolução da Bioética tem provocado ${ }^{(10)}$. Dentre as razões pelas quais 0 autor faz esta proposta, salientamos as seguintes:

- "porque satisfaz à exigências éticas atuais de a pessoa ser vista como sujeito e protagonista, usuário crítico, livre e responsável dos serviços de saúde;

- porque restitui à pessoa sua competência moral;

- porque sensibiliza o reconhecimento dos problemas éticos no âmbito da saúde e da vida de forma recíproca: o "outro" (alter) também "sou eu";

- porque significa a solidariedade comum e a responsabilidade recíproca;

- porque rompe com o paternalismo e 0 absolutismo freqüentes na área da saúde (profissional $x$ cliente), onde 0 cliente é visto mais como recipiente de ordens;

- porque torna a relação profissional $x$ cliente uma relação de colaboração em atitude adulta, conferindo respeito mútuo"(10).

Acreditamos que as tais razões devem estar presentes no cenário da ação gerencial do enfermeiro, levando em conta sua própria atuação, bem como a dos integrantes da equipe de enfermagem, uma vez que o exercício legítimo da praxis de alteridade implica, necessariamente, no livre consentimento do paciente. E mais, esta conduta estabelece mútuas responsabilidades: a do profissional de enfermagem e a do paciente. Esta interação, então, confere uma nova atitude prática mais condizente com a nossa visão e com a nossa época, tão desejosa de relacionamento adulto, personalizado, igualitário e justo! Nesse sentido, reiterou-se a importância dos valores compartilhados, sob alegação de que qualquer estratégia será vazia de significado se não considerarmos a relevância das aspirações e das crenças compartidas entre o enfermeiro e a equipe de enfermagem $^{(11)}$. Os enfermeiros podem assumir responsabilidade pela promoção e proteção de valores, os quais são utilizados na condução do trabalho, na tomada de decisões, ao mesmo tempo que oferecem uma estrutura para dar suporte à autonomia do trabalhador $^{(12)}$.

Tratando da ética no contexto gerencial do enfermeiro, em nível hospitalar, não podemos deixar de mencionar alguns dos princípios constantes do Código de Ética do Hospital Brasileiro ${ }^{(13)}$, aprovado em 1985 pela Comissão de Saúde da Câmara dos Deputados:

- "o bom funcionamento do hospital envolve responsabilidades específicas, concernentes à dignidade do paciente, em todos os estágios da sua internação; ao seu direito de determinar o que deseja ou aceita; à defesa da sua vida e à promoção da sua saúde...

- o quadro de pessoal e o corpo clínico do hospital devem ser: suficientes para a prestação dos serviços a que se propõem; plenamente habilitados, do ponto de vista profissional; e conscientemente motivados pelos compromissos éticos em relação ao paciente. Nessas condições, a administração respeitará integralmente a competência específica dos profissionais incumbidos do atendimento dos pacientes, e a responsabilidade correlata pelas prescrições que fizerem...

- o paciente e/ou seu responsável legal têm direito irrestrito a toda informação referente à sua saúde, ao tratamento prescrito, às alternativas disponíveis e aos riscos e contra-indicações implícitas em cada uma destas. É reconhecido ao paciente o direito - igualmente irrestrito - de recusar determinado tratamento" ${ }^{\text {"(13) }}$

O cliente, ou seu responsável, tem "o direito de saber todos os dados a respeito do seu corpo, de sua saúde ou de sua doença, uma vez que esse corpo, essa saúde e inclusive a doença the pertencem, e não ao médico"(14). 0 paciente permite e autoriza 0 médico ou o profissional de saúde a lidar com ele, mas não the concede 0 direito de decidir por ele.

No ambiente hospitalar, os enfermeiros, mais do que qualquer outro profissional da saúde, têm freqüentes oportunidades de facilitar e manifestar o respeito pelos direitos dos pacientes. Como líderes de equipe, ou seja, assumindo a liderança da assistência prestada ao paciente, os enfermeiros são a fonte principal de contato pessoal, íntimo e contínuo com os pacientes, não obstante seu envolvimento com a tecnologia e com a burocracia hospitalar. São eles os responsáveis pela implementação do cuidado a cada paciente, individualmente, o que lhes confere oportunidade de orientá-lo e de prestar-lhe informações completas, precisas e verdadeiras sobre os procedimentos que os integrantes da equipe de enfermagem, ou outros profissionais da saúde, desempenharão com ele e para ele.

Mas, para que o enfermeiro consiga promover o paciente como sujeito e protagonista de seu cuidado e tratamento é preciso que este apresente condições de participação, ou seja, habilidade de comunicar-se e de compreender informações e habilidade de raciocinar e deliberar sobre sua escolha, segundo seu próprio conjunto de valores e metas ${ }^{(15)}$. Em países de terceiro mundo, o esforço do enfermeiro no sentido de promover a participação do paciente é maior, porque grande parte deles não apresenta as referidas condições.

Finalizando, cabe acrescentar que, em relação ao consentimento, a literatura ilustra problemas enfrentados por enfermeiros, onde encontra-se registros de que a preocupação dos enfermeiros com o consentimento informado para a prática médica desvia o seu foco de atenção, que deve estar dirigido para a importância do consentimento do paciente para a prática de enfermagem. $E$ se os pacientes têm o direito de recusar tratamentos médicos ou cirúrgicos, o mesmo se aplica para intervenções de enfermagem $^{(16)}$. 


\section{REFERÊNCIAS BIBLIOGRÁFICAS}

1. Etzioni A. Análise comparativa de organizações complexas: sobre o poder, o engajamento e seus correlatos. Rio de Janeiro (RJ): Zahar; 1974.

2. Handy CB. Como compreender as organizações. Rio de Janeiro (RJ): Zahar; 1978.

3. Rosenow AM. Professional nursing practice in the bureaucratic hospital - revisited. Nursing Outlook 1983; 31(1):34-9.

4. Trevizan MA, Mendes IAC, Ferraz CA, Évora YDM, Ventura CAA. Struggling for the establishment of a new ethics to nurses' managerial work. Proceedings of the $12^{\text {th }}$ World Congress on Medical Law; 1998.

Siófok, Hungary. 1998. Budapest, World Association for Medical Law; 1998. p.656-66.

5. Conselho Federal de Enfermagem (BR). Código de ética dos profissionais de enfermagem. Rio de Janeiro; 1993.

6. Trevizan MA. Enfermagem hospitalar: administração \& burocracia. Brasília (DF): UnB; 1988.

7. Vasquez AS. Filosofia da práxis. 2.ed. Rio de Janeiro (RJ): Paz e Terra; 1977.

8. Leis, Decretos, etc. (BR). Lein 7.498, de 25/06/1986. Dispõe sobre a regulamentação do exercício da enfermagem. D.O.U., 26/06/1986. In: COFEn - Normas e Notícias, 1986; 9(2).
9. Barchifontaine CP, Pessini L. Problemas atuais de Bioética. São Paulo (SP): Edições Loyola; 1991.

10. Correia FA. A alteridade como critério fundamental e englobante da bioética. [tese]. Campinas (SP): Faculdade de Educação/ UNICAMP; 1993.

11. Trevizan MA, Mendes IAC, Galvão CM, Sawada NO. A new ethics to nurse's management action: shared values. Proceedings of the $11^{\text {th }}$ World Congress On Medical Law, Sun City, South Africa 1996. South Africa, World Association for Medical Law; 1996. p.473-81.

12. Trevizan MA, Mendes IAC. Perspectives of participative management in nursing. Applied Nursing Research 1995; 8(4):1569.

13. Brasil. Comissão de Saúde da Câmara dos Deputados. Código de Ética do Hospital Brasileiro. In: Barchifontaine CP, Pessini L. Problemas atuais de Bioética. São Paulo (SP): Edições Loyola; 1991. p. 311-3.

14. Gauderer EC. Os direitos do paciente: um manual de sobrevivência. Rio de Janeiro (RJ): Record; 1991.

15. Bandman EL, Bandman B. Nursing ethics through the life span. $2^{\text {nd }}$ ed. Englewood Cliffs (NJ): Prentice Hall; 1990.

16.Curtin LL. Ethics in management. Informed consent: cautious, calculated candor. Nursing Management 1993 April; 24(4):18-20. 